\title{
Rejoinder to \\ Evidence and the micro-foundations of economic growth by Michael Joffe
}

\author{
Emma Hamilton ${ }^{1}$
}

There's nothing so practical as good theory

(Lewin, 1951)

This is a response to Joffe (this issue (Joffe, 2017b)) and aims to demonstrate that economics needs theory that is developed in collaboration with real-world data and that approaches utilised in other disciplines may be transferred to enable this goal. Building better theory will enable improved explanation of economic phenomena to aid the understanding of causation in interacting systems. In turn, this will allow more effective application to policy problems as such theory can inform intervention within these systems. With poor theory, data collection, analysis and interpretation can all be misdirected and misleading.

\section{New thinking from the OECD}

The OECD amongst others has noted various shortcomings of economics, how it is applied and how disciplinary change could be encouraged. It responded to the post-crisis calls for change with the New Approaches to Economic Challenges (NAEC) initiative (http://www.oecd.org/naec/) launched in 2012. This is 'a comprehensive organisation-wide reflection process which is triggering and accelerating a revision of the OECD's analytical frameworks [and] its policy instruments and tools' (OECD, 2015, p. 3). One of the intended goals of this is 'to build a new policy agenda for stronger, more resilient, inclusive and sustainable growth' (OECD, 2015, p. 3).

The OECD argues that a new approach is needed 'that integrates behavioural economics and complex systems theory, as well as economic history. We also need a new narrative to integrate all these different, often conflicting influences.

\footnotetext{
${ }^{1}$ Arcola Research LLP, 6 Alvington Crescent, London E8 2NW, United Kingdom; emma.7.hamilton@gmail.com.
} 
... [A] new narrative ... should be based on the best facts and science available, and contain ... a new story of growth' (Ramos, 2017). They suggest that 'the more complex and open-ended interactions between the political, economic, social and ecological systems mean that policymakers need access to a wider range of systems sciences and techniques. This is not to dethrone macroeconomics as a dominant policy science, but it does call for a more eclectic and disaggregated approach to policy analysis' (OECD, 2017, p. 61).

Hence, one implication of this thinking is that macroeconomic theories need to take seriously this orientation so as to stay relevant and provide appropriate policy analysis and advice.

\section{Problems with growth theory}

The OECD asserts that there is a need for a new theory of growth that is both based on real-world facts, and that elucidates interactions with inequality, wellbeing and the environment. In the past growth has been analysed 'too narrowly as an end, rather than a means to improve societal well-being' (OECD, 2015, p. 3). Hence, the way in which current mainstream growth theories are constructed is problematic. Too often the consequences of growth for inequality, the environment and ultimately well-being are excluded from analysis.

If all of the phenomena surrounding economic growth were suitably modelled and took account of a broader evidence base, it should be possible to say something more reliable and relevant for policy makers. To do this, growth theory would include both the causes of types of growth; and the effects of types of growth on inequality, well-being and the environment. This could have the potential to increase the ability of governments to achieve balanced growth that takes into account these broad understandings.

\section{Lessons from other disciplines}

To undertake evidence-based theory development in causal systems, moving away from the norm of deductive theory development, economics can learn from other disciplines that operate in similar contexts. Three examples are biology, geology (Joffe, 2017a) and political science (Befani, 2012; Byrne \& Callaghan, 2013), all of which operate with complex phenomena and systems. The following sections provide examples of case-study approaches utilised in political science that could contribute to evidence-based theory development in economics.

The proposal here is for economics to build on experience carrying out multimethod research, combining within-case analysis and cross-case analysis. Policy advice by economists tends to build on large-scale cross-case analysis 
ignoring what happens within cases. Bridging macro- and micro-economic or structural factors is also under-theorised. I am arguing that only the opening up of the 'black box' of 'the case' would allow close analysis of causal mechanisms or conditions, in support of causal inference. Cross-case analysis may demonstrate the distribution of causal patterns but it is ill-suited to identifying complex interactions within sub-types of cases.

If one accepts the need to better understand of causal systems, we need appropriate methods, even for theory development. Other social science disciplines have struggled with similar demands. Political science has focussed on variants of set-theoretic cross-case methods (see for example, Qualitative Comparative Analysis [QCA] and typological theory [TT]) - and their combination with a within-case method (e.g. process tracing [PT]). They are compatible with each other, and share a set-theoretic conceptualization of causal relationships (Beach \& Rohlfing, 2015). ${ }^{2}$ This is key because it enables the analysis of mechanisms and what has been called 'conjunctural causation' where 'the causal relation is to be established between an effect and a combination of multiple causes, a causal package, rather than a single cause' (Befani, 2013, p. 271).

While a cross-case method (e.g. QCA or TT) enables the study of set-relational patterns across the population, these patterns do not focus on causation. A within-case method (e.g. PT), involving the in-depth study of causal mechanisms in a single case, can be used to better understand the causal mechanisms between the relevant variables established by cross-case analysis. The complementary use of cross-case analysis with within-case analysis can be used to assess 'whether the insights gathered via [the latter] extend beyond the examined case' (Beach \& Rohlfing, 2015, p. 3). The argument here is that for theorybuilding purposes these kinds of methods are especially helpful.

In the space available I have highlighted QCA/TT and PT as particular methodological exemplars. Of course there are others that are useful for theory development: for example, the NAEC initiative also identified network analysis; various non-linear modelling and simulation approaches such as agent-based modelling and system dynamics; using systems thinking and complexity science to build better theory; and better integrating qualitative analysis into quantitative designs as with foresight studies. It is widely acknowledged that many of these approaches are new and still under-developed. There are also unresolved issues combining these approaches, which are also limited when analysing large data sets. However there is increasing experience about how to overcome obstacles and the benefits appear to outweigh the costs (with respect to QCA/TT and PT, see the special issue of Sociological Methods \& Research introduced in Beach \& Rohlfing, 2015). Developing theory is needed if we want to take account of real-world evidence in areas such as economic growth and well-being.

\footnotetext{
${ }^{2}$ Space does not allow for a full description of these approaches; a good source for this is the special issue of Sociological Methods \& Research introduced in Beach and Rohlfing (2015).
} 


\section{Conclusions}

Following the initiative from the OECD investigating 'new approaches to economic challenges', this contribution has argued that economics needs theory that is developed in collaboration with real-world data and appreciation of different causal systems.

Such theory will enable improved explanation of economic phenomena to aid the understanding of causation in interacting systems. This will allow more effective application to policy problems by bodies such as the OECD - as such theory can inform intervention within these systems. As an example, current growth theory is problematic, both in terms of its empirical basis and lack of situation in interacting systems. This and other economic theory may possibly be updated through approaches utilised in other disciplines.

This paper has suggested carrying out multimethod research, combining within-case analysis and cross-case analysis. The within-case in-depth study can provide evidence of causal mechanisms while the cross-case analysis can demonstrate the distribution of causal patterns. Additionally, set-theoretic within-case and cross-case methods are proposed, as they enable the analysis of mechanisms and 'conjunctural causation', both characteristics of causal systems.

\section{References}

Beach, D., \& Rohlfing, I. (2015). Integrating cross-case analyses and process tracing in set-theoretic research: Strategies and parameters of debate. Sociological Methods \& Research, 49124115613780. https://doi.org/10.1177/0049124115613780

Befani, B. (2012). Models of causality and causal inference. In E. Stern, N. Stame, J. Mayne, K. Forss, R. Davies, \& B. Befani (Eds.), Broadening the range of methods for impact evaluations. Retrieved from www.dfid.gov.uk/r4d/Output/189575/ Default.aspx

Befani, B. (2013). Between complexity and generalization: Addressing evaluation challenges with QCA. Evaluation, 19(3), 269-283. https://doi.org/10.1177/1474022213493839

Byrne, D., \& Callaghan, G. (2013). Complexity theory and the social sciences (1 edition). New York: Routledge.

Joffe, M. (2017a). Causal theories, models and evidence in economics - some reflections from the natural sciences. Cogent Economics \& Finance, 5(1), 1280983. https:// doi.org/10.1080/23322039.2017.1280983

Joffe, M. (2017b). Evidence and the micro-foundations of economic growth. Economics and Business Review.

Lewin, K. (1951). In D. Cartwright, Field theory in social science: Selected theoretical papers. New York: Harper Row.

OECD. (2015). Final naec synthesis: New approaches to economic challenges. 
OECD. (2017). New approaches to economic challenges: Towards a new narrative. Retrieved from http://oecdinsights.org/2017/06/23/we-need-an-empowering-narrative

Ramos, G. (2017, June 23). We need an empowering narrative. Retrieved 17 August 2017, from http://oecdinsights.org/2017/06/23/we-need-an-empowering-narrative/ 